\title{
Hybrid numerical-analytical model for force prediction in end milling
}

\author{
Modelowanie sił podczas frezowania walcowo-czołowego \\ w oparciu o hybrydowy model numeryczno-analityczny
}

\author{
MAREK MADAJEWSKI \\ SZYMON WOJCIECHOWSKI \\ NATALIA ZNOJKIEWICZ \\ PAWEŁ TWARDOWSKI *
}

Presented is method for prediction of cutting force components during end milling process by utilizing finite element analysis (FEA) combined with classical analytical approach. Hybrid model predicts $F_{f}$ and $F_{f N}$ force components which are compared with empirical measurements from milling operation.

KEYWORDS: finite element analysis, modelling, force components, end milling

Numerical technique - finite element method (FEM) - was used by researchers dealing with machining at the turn of the 1970s and 1980s. Due to the high complexity of the problem, the cutting analysis was limited to the orthogonal model. This treatment was to bring the problem to a plane strain, to facilitate the modeling of geometry and to limit the number of degrees of freedom. Despite such far-reaching simplifications, modeling of the machining process in FEM software presents many problems, which even today is dominated by two-dimensional models in scientific publications $[3,6,8]$. Orthogonal models, although seemingly simple, provide researchers with a unique insight into the cutting zone, but are still often insufficient to solve problems in the industry.

The paper presents a hybrid numerical-analytical model for prediction of forces during end milling of $42 \mathrm{CrMo} 4$ stee (40HM) [4, 5]. In the model, the FEM simulation was used to determine the correct specific cutting force for a given tool geometry in orthogonal cutting. These data, in turn, using an analytical model based on the Altintas mechanical model [1], will be converted into forces acting in the machine tool system for the variable uncut chip thickness during milling. This approach to the problem can be applied at the design stage of monolithic milling cutters prior to prototyping.

\footnotetext{
* Mgr inż. Marek Madajewski (marek.w.madajewski@doctorate.put. poznan.pl), dr inż. Szymon Wojciechowski (szymon.wojciechowski@ put.poznan.pl), mgr inż. Natalia Znojkiewicz (natlia.w.znojkiewicz@ doctorate.put.poznan.pl),dr hab. inż. Paweł Twardowski prof. PP (pawel.twardowski@put.poznan.pl) - Zakład Obróbki Skrawaniem Politechniki Poznańskiej
}

\section{FEM model for chip forming}

The orthogonal cutting model used to determine the specific cutting force for plane strain was prepared in the ABAQUS program. Its assumptions are presented in fig. 1.

The proposed model requires a pre-defined shape of the chip, taking into account the geometry of the tool and cutting parameters. The model is constructed from two types of surfaces: free Lagrange type (black full line) and from defined Euler surfaces (red dotted line) [4, 6].

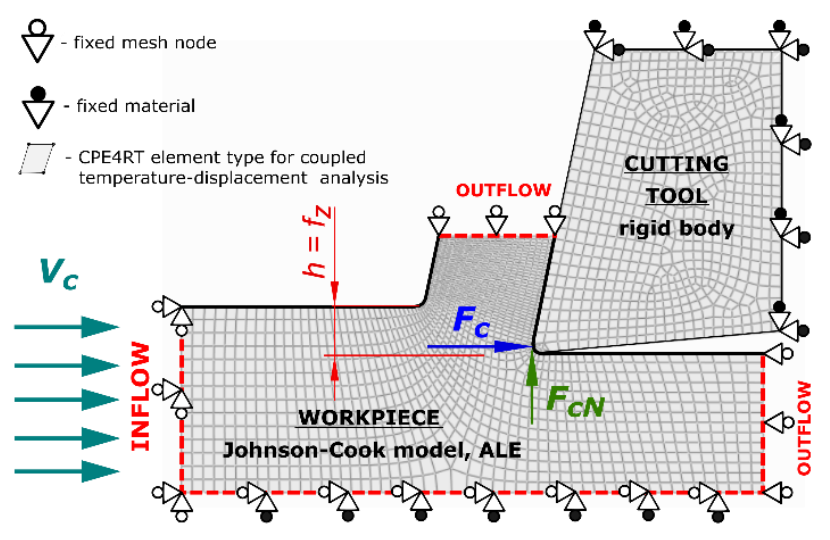

Fig. 1. FEM model of orthogonal cutting

In Lagrange-type surfaces, material and mesh movement are related to each other, whereas in Euler-type surfaces material and mesh node motions are independent of each other, and the material can flow through the mesh of finite elements. The problem model defined in this way behaves like a crust through which material flows at a given speed.

The material pressing through the free Lagrange surface on the tool, modeled as a rigid body, causes pressure on the rake and flank surfaces, which are recorded as a horizontal and vertical component of the total force. Chip geometry is modified along with the course of the simulation and aims to achieve a steady state (in which the results do not change significantly over time). The feed parameter $f_{z}$ is identical to the thickness of the cutting layer $h$, and the cutting speed $v_{c}$ is given as a boundary condition of the velocity type, which determines the material flow speed 
through the inflow surface. The depth of cut $a_{p}$ is defined as the thickness of the workpiece section in a direction perpendicular to the plane of the drawing.

During the simulation, it is recommended to use the algorithm ALE (Arbitrary Lagrangian-Eulerian), which in regular intervals of time simulates smoothes and maintains the correct proportions of the grid despite significant deformation of the object. The material model does not contain the conditions of damage or decohesion, as the formation of the chip takes place by specifying the material flow paths (outflow).

\section{Analytical model of milling}

An overall mechanistic model was used to predict the course of forces during end milling $[1,3,4]$. The model was implemented in the MATLAB program, and its simplified scheme is shown in fig. 2 together with the most important dependencies.

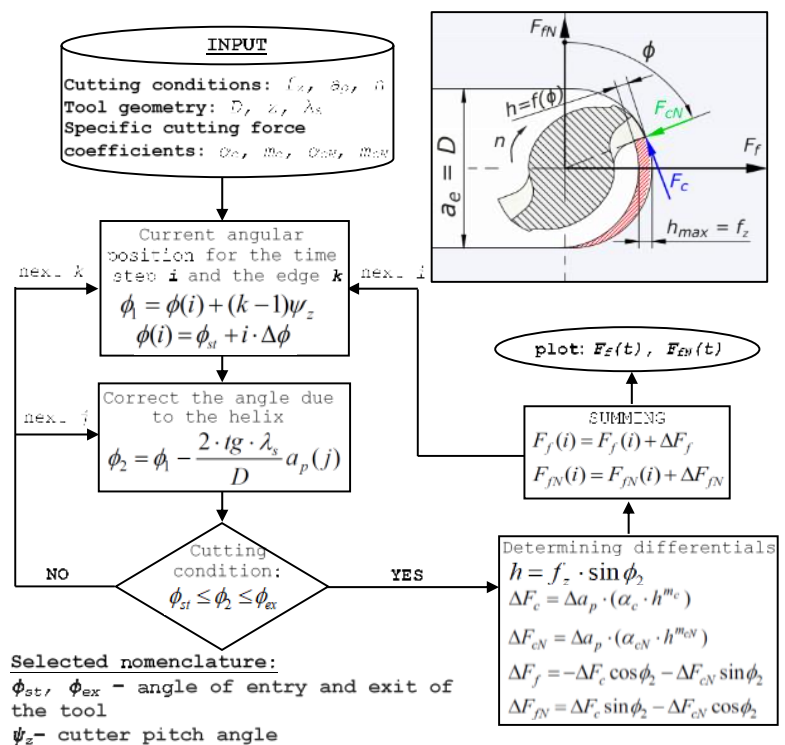

$\psi_{z}-$ cutter pitch angle
$\Delta a_{p}-$ incremental cutting depth

Fig. 2. Simplified diagram of the force model in the machine tool coordinates for an end mill

In the model, the specific cutting force coefficients $k_{\mathrm{c}}$ and $k_{\mathrm{cN}}$ are used, which for the given geometry of the tool and the selected workpiece have been determined by numerical modeling and modeled by the regression equation. The purpose of this code is to transform the components of the total force $F_{\mathrm{c}}$ and $F_{\mathrm{cN}}$ from the tool system in orthogonal cutting into the machine tool arrangement as forces $F_{f}$ and $F_{\mathrm{fN}}$, taking into account the number of cutting edges or the angle of inclination of the main cutting edge $\lambda_{\mathrm{s}}$.

The use of the mechanistic model makes it possible to determine the uncut chip thickness as a function of the cutter rotation angle based on the simple trigonometric relation. Therefore, the forces in the machine system will change in a sinusoidal manner.

By setting parameters $f_{z}$ and $a_{p}$ for the range tested, it will be possible to predict the forces as a function of the angle of rotation or the cutting time for the cutter with the number of teeth $z$.

\section{Constitutive model and material constants}

Stresses in the workpiece were determined using the Johnson-Cook's constitutive model [2]. This model makes it possible to determine the reduced Huber-Mises-Hencky stress depending on the deformation, strain rate and temperature. The model is expressed in the form:

$$
\sigma_{y}=\left(\mathrm{A}+\mathrm{B} \varepsilon_{p}^{\mathrm{n}}\right)\left(1+\mathrm{C} \ln \left(\frac{\dot{\varepsilon}_{p}}{\dot{\varepsilon}_{\mathrm{p}}^{0}}\right)\right)\left(1-\left(\frac{T-\mathrm{T}_{\mathrm{o}}}{\mathrm{T}_{\mathrm{t}}-\mathrm{T}_{\mathrm{o}}}\right)^{\mathrm{m}}\right)
$$

where independent variables belong: $\varepsilon_{p}$ - equivalent plastic strain, $\boldsymbol{\varepsilon}$ - equivalent plastic strain rate and $T$ - temperature. The model also requires the definition of thermo-mechanical constants, which are summarized in the table with the parameters of the $\mathrm{J}-\mathrm{C}$ model for $42 \mathrm{CrMo} 4$ steel.

TABLE. Parameters of the Johnson-Cook equation for 42CrMo4 steel and thermomechanical constants $[7,8]$

\begin{tabular}{|c|c|c|c|c|}
\hline \multicolumn{2}{|c|}{$\begin{array}{c}\mathrm{J}-\mathrm{C} \text { model for steel } \\
\text { 42CrMo4 }\end{array}$} & $\begin{array}{l}\text { Thermomecha- } \\
\text { nical constants }\end{array}$ & Steel & $\begin{array}{l}\text { Sintered } \\
\text { carbide }\end{array}$ \\
\hline $\begin{array}{l}\text { yield stress coeffi- } \\
\text { cient } A, \mathrm{MPa}\end{array}$ & 852 & $\begin{array}{l}\text { density } \rho \\
\mathrm{kg} / \mathrm{m}^{3}\end{array}$ & 7850 & 15000 \\
\hline $\begin{array}{l}\text { strain hardening } \\
\text { coefficient } B, \mathrm{MPa}\end{array}$ & 1102 & $\begin{array}{l}\text { young's modu- } \\
\text { lus } E, \mathrm{GPa}\end{array}$ & 210 & 800 \\
\hline $\begin{array}{l}\text { strain rate sensitivity } \\
\text { coefficient } C\end{array}$ & $8 \mathrm{E}-3$ & $\begin{array}{l}\text { poisson's ratio } \\
V\end{array}$ & 0.3 & 0.2 \\
\hline $\begin{array}{l}\text { strain hardening } \\
\text { exponent coeff. } n\end{array}$ & 0.7 & $\begin{array}{l}\text { thermal conduc- } \\
\text { tivity } \lambda, \mathrm{W} / \mathrm{m} \cdot \mathrm{K}\end{array}$ & 38 & 80 \\
\hline $\begin{array}{l}\text { thermal softening } \\
\text { coefficient } m\end{array}$ & 1.0 & $\begin{array}{l}\text { specific heat, } \\
C_{\mathrm{p}}, \mathrm{J} / \mathrm{kg} \cdot \mathrm{K}\end{array}$ & 358 & 203 \\
\hline $\begin{array}{l}\text { reference strain } \\
\text { rate } \dot{\bar{\varepsilon}}_{0}, \mathrm{~s}^{-1}\end{array}$ & 1000 & $\begin{array}{l}\text { coefficient of } \\
\text { friction } \mu\end{array}$ & & 0.4 \\
\hline $\begin{array}{l}\text { reference tempe- } \\
\text { rature } T_{0}, \mathrm{~K}\end{array}$ & 300 & & & \\
\hline $\begin{array}{l}\text { melting } \\
\text { temperature } \\
T_{\mathrm{t}}, \mathrm{K}\end{array}$ & 1783 & & & \\
\hline
\end{tabular}

\section{Measuring stand and testing conditions}

In order to verify the hybrid force model during end milling, empirical studies were carried out on a DMG threeaxis milling center type DMC70V. The Fraisa sintered carbide milling cutter with diameter $\varnothing 12 \mathrm{~mm}$ and number of teeth $z=2$ was used (fig. $3 a-1$, fig. $3 c$ ), rake angle $y_{0}=12^{\circ}$, flank angle $\alpha_{0}=5^{\circ}$ and angle of inclination of the main cutting edge $\lambda_{\mathrm{s}}=30^{\circ}$.

The workpiece (fig. 3a-3) was a $42 \mathrm{CrMo} 4$ steel block with a hardness of $13 \div 14 \mathrm{HRC}$, mounted in a vice (fig. 3a-4), connected to a piezoelectric dynamometer (Figures 3a-5). The signal from the dynamometer was transferred to the Kistler amplifier and recorded on the computer with a sampling frequency of approx. $10,000 \mathrm{~Hz}$.
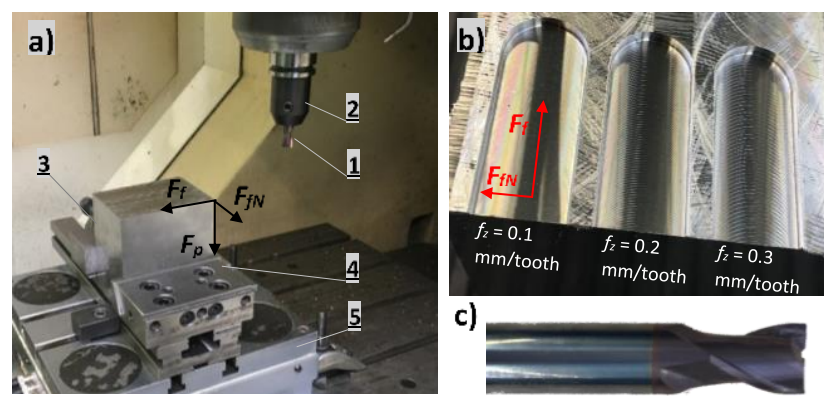

Fig. 3. Setup for measurement of forces during milling (a), workpiece after the end of experimental tests (b), used cutter Fraisa U5400 $D=12 \mathrm{~mm}$ (c)

Force measurements were made for a total of nine milling passes over a length of $50 \mathrm{~mm}$ (fig. 3b), for a combination of parameters $f_{z}: 0.1 ; 0.2 ; 0.3 \mathrm{~mm} /$ tooth and $a_{\mathrm{p}}$ : $0.25 ; 0.5 ; 1.0 \mathrm{~mm}$. Cutting with the full diameter of the milling cutter $\left(a_{e}=12 \mathrm{~mm}\right)$ for $v_{c}=150 \mathrm{~m} / \mathrm{min}$. The same parameters were adopted in the analytical model and FEM.

The three-component piezoelectric dynamometer measured the total component forces in the directions 
parallel to the machine axis: feed normal $F_{\mathrm{fN}}$, feed $F_{\mathrm{f}}$ and thrust force $F_{\mathrm{p}}$.

\section{Research results and their analysis}

Fig. 4a presents the average values of the specific cutting forces obtained from the FEM research together with the applied regression model in the form of a power function. For each thickness $h$ the average value of the specific cutting force was taken, resulting from three simulations carried out with different depths $a_{p}$. The range values obtained in this way did not exceed $7 \%$ for $k_{\mathrm{cN}}$ and $2.3 \%$ for $k_{c}$. Regardless of the thickness of the cut $h$, the values of $k_{\mathrm{c}}$ and $k_{\mathrm{cN}}$ changed randomly with respect to the tested cutting depths $a_{p}$. The results of the simulation confirm the known dependence that the depth of $a_{p}$ cutting has no significant effect on the value of the specific cutting forces.

Fig. $4 \mathrm{~b}$ shows the distribution of reduced Huber-MisesHencky stress in the chip layer for selected cutting data. It is possible to extract the high stress band in the shear plane. This confirms the legitimacy of using this model to model the machining process.
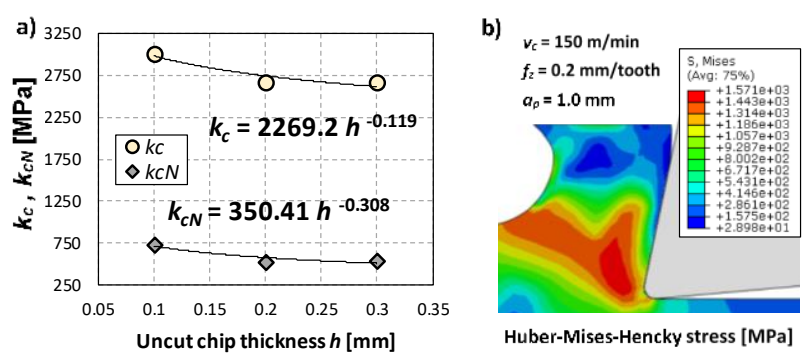

Fig. 4. Model for average values of the specific cutting resistance based on FEM (a), distribution of stresses in the chip layer (b)

Fig. 5 and fig. 6 present a comparison of the components of total force from experimental tests (unfiltered signal) with a numerical-analytical model on two examples. The time series of the $F_{\mathrm{fN}}$ and $F_{\mathrm{f}}$ components, estimated based on the hybrid model, show a high compatibility with the experimental runs. However, in the case of time courses of the modeled component $F_{\mathrm{fN}}$, for $f_{z}=0.1 \mathrm{~mm} /$ tooth, $a_{p}=0.5$ $\mathrm{mm}$, and the component $F_{\mathrm{f}}$, for $f_{\mathrm{z}}=0.2 \mathrm{~mm} /$ tooth and $a_{\mathrm{p}}=$ $1.0 \mathrm{~mm}$, there is underestimation in relation to experimental values.

Despite this underestimation, the model maps the characteristic course of these two components of the total force, where the force $F_{\mathrm{f}}$ oscillates asymmetrically with respect to the zero value, and the component $F_{\mathrm{fN}}$ is periodically variable and increases from zero to the maximum value. As potential causes of the underestimation error one can indicate the a priori assumption of a constant value of the coefficient of friction for the whole series of tests, differences in properties of the material tested and material for which the Johnson-Cook constitutive model was prepared, and the performance of individual experimental tests for each set cutting parameters. However, the most important factor affecting the differences - both qualitative and quantitative - in the course of forces is the difference in stiffness of the proposed theoretical and real model of the machining system under study.

The forces measured in experimental tests depend not only on the cross-section of the cut, but also on the rigidity and inertia of the machining system, which determine the presence of displacements of the working part of the tool. As a consequence, it has an influence on fluctuations in the cross-section of the cut as a function of the tool rotation angle, and thus also on the variation of instantaneous force values. However, the proposed hybrid model is based on trigonometric relationships, and the cutting tool is designed as a perfectly rigid body.
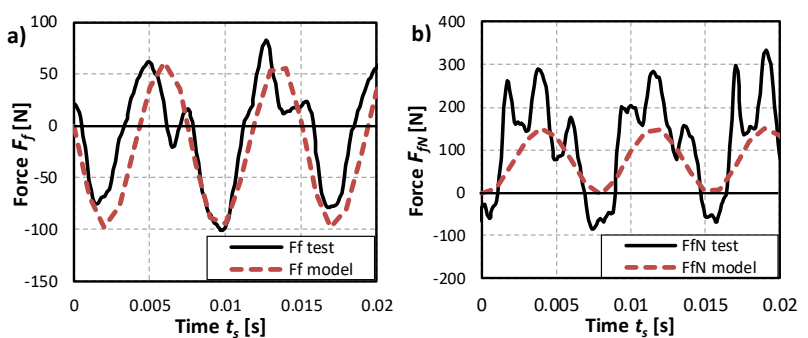

Fig. 5. Comparison of force components from experimental and hybrid model for $f_{z}=0.1 \mathrm{~mm} /$ tooth and $a_{p}=0.5 \mathrm{~mm}$
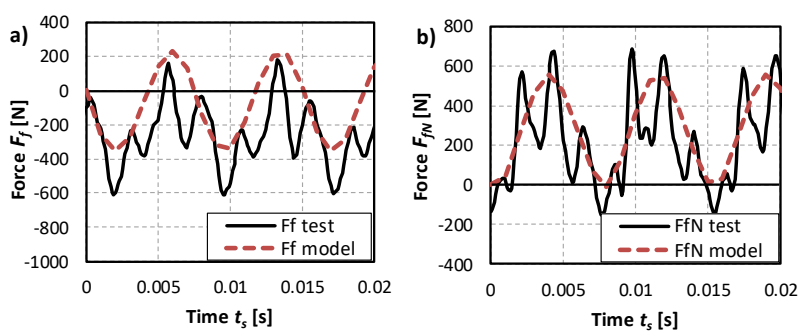

Fig. 6. Comparison of force components from experimental and hybrid model for $f_{z}=0.2 \mathrm{~mm} /$ tooth and $a_{p}=1.0 \mathrm{~mm}$

\section{Conclusions}

- FEM chip formation model, based on Johnson-Cook's constitutive equation with predefined chip geometry with Lagrange and Euler surfaces, allows to effectively model the orthogonal cutting process. This validates the occurrence in the model of the shear plane characterized by a band of high equivalent stresses of $1.3 \div 1.56 \mathrm{GPa}$ and the detachment of the chip from the rake face (fig. 4b).

- Computer simulations have confirmed the known dependence that the specific cutting force depends primarily on the thickness of the machined layer and not on the depth of cut. With a constant thickness of the cut $h$, when the values of $k_{\mathrm{c}}$ and $k_{\mathrm{c}}$ changed randomly in function of the depth of $a_{p}$ cutting, the discrepancy of results reached only a few percent. This allows increasing the application range of the hybrid model beyond the tested $a_{p}$ range.

- Hybrid model of end milling represents the total force components $\left(F_{\mathrm{f}}\right.$ and $\left.F_{\mathrm{fN}}\right)$ in a satisfactory manner. However, in some cases, significant differences in force values are observed, reaching $259 \mathrm{~N}$. Differences of a similar order were observed in studies [4]. The main source of model deviations from the experimental course of forces is the dynamics of the machining system.

\section{REFERENCES}

1. Altintas Y. "Manufacturing Automation". Cambridge: CUP, 2012.

2. Cook W.H., Johnson G.R. "A constitutive model and data for metals subjected to large strains, high strain rates and high temperatures". Proc. of the $7^{\text {th }}$ Int. Symposium on Ballistics (1983).

3. Ducobu F., Rivière-Lorphèvre E., Filippi E. "Finite element modelling of 3D orthogonal cutting experimental tests with the Coupled Eulerian-Lagrangian (CEL) formulation". Finite Elements in Analysis and Design. 134 (2017): pp. 27-40.

4. Jin X., Altintas Y. "Prediction of micro-milling forces with finite element method". Journal of Materials Processing Technology. 212 (2012): pp. 542-552.

5. Jing X., Li H., Wang J., Tian Y. "Modelling the cutting forces in micro-end-milling using a hybrid approach". Int. Journal of Advanced Manufacturing Technology. 74 (2014).

6. Mashayekhi M., Salimi M., Vaziri M.R. "Evaluation of chip formation simulation models for material separation in the pres- 
ence of damage models". Simulation Modelling Practice and Theory. 19 (2011): pp. 718-733.

7. Moćko W. "Effects of cumulative fatigue damage under tensional cyclic loading on the constitutive relation of AISI 1045 steel". Proc. of the $4^{\text {th }}$ Int. Conference on Nonlinear Dynamics (2013)

8. Pantale O. " $2 \mathrm{D}$ and $3 \mathrm{D}$ numerical models of metal cutting with damage effects". Computer Methods in Applied Mechanics and Engineering. 193 (2004): pp. 4383-4399.

Translation of scientific articles, their computer composition and publishing them on the website www.mechanik.media.pl by original articles in Polish is a task financed from the funds of the Ministry of Science and Higher Education designated for dissemination of science. 